УДК 372.8+378.018.43

\title{
ПРОСТЫЕ МЕТОДЫ В НЕПРОСТЫХ УСЛОВИЯХ: ПРИМЕНЕНИЕ РЕДАКТОРА ПРЕЗЕНТАЦИЙ РОWЕRРОINT И GOOGLE-ФOРМ ДЛЯ ПОДГОТОВКИ ВИДЕОЛЕКЦИЙ
}

Гундырев Вадим Борисович к.пед.н., доцент

Королева Евгения Николаевна старший преподаватель Лосев Виктор Васильевич к.ф.-м.н., профессор

Морозова Тамара Владимировна к.т.н., доцент Национальный исследовательский университет «МИЭТ» г. Москва, г. Зеленоград

Аннотация: В статье рассмотрены вопросы самостоятельного создания качественного видеоконтента для проведения дистанционных занятий в школе и вузе без использования сложного аппаратного и программного оборудования. Продемонстрирован опыт создания видео с помощью редактора презентаций PowerPoint с использованием сотового телефона для получение фото- и видеоматериала и последующим размещением видео на канале YouTube, a также интеграция видео в смысловой логический блок с использованием Google-форм.

Ключевые слова: дистанционное образование, дистанционные образовательные технологии, дистанционное обучение, онлайн-обучение, PowerPoint, Google-формы.

SIMPLE METHODS IN DIFFICULT CONDITIONS. USE THE POWERPOINT PRESENTATION EDITOR AND GOOGLE FORMS TO PREPARE VIDEO LECTURES

Vadim Borisovich Gundyrev Korolyova Evgenia Nikolaevna Losev Viktor Vasilyevich Tamara V. Morozova 


\section{ОБРАЗОВАТЕЛЬНЫЕ ТЕХНОЛОГИИ

Abstract: The article deals with the issues of self-creation of high-quality video content for remote classes at school and university without the use of complex hardware and software equipment. The experience of creating videos using the PowerPoint presentation editor using a cell phone to get photos and videos and then post the video on the YouTube channel, as well as integrating the video into a semantic logical block using Google forms, is demonstrated.

Key words: distance education, distance learning technologies, distance learning, online learning, PowerPoint, Google forms.

Продолжающаяся уже более года пандемия выявила ряд характерных тенденций в развитии как информационных технологий, средств коммуникации так и в способности общества реагировать на эти изменения. Так, со всей очевидностью стало понятно, что количество профессий, не нуждающихся в строгом структурировании рабочего времени и рабочего места, иными словами, не требующие ни офиса, ни строгого графика работы, гораздо больше, чем казалось ещё полтора года назад, в начале 2020 года. Так, проектная организация может позволить своим сотрудникам дистанционную работу, собирая их, допустим, раз в неделю для совместного обсуждения проблем. Мало того, что подобное обсуждение также может быть дистанционным, но даже в очном формате оно существенно снижает нагрузку на инфраструктуру как общественную, так и данной организации. Вообще говоря, можно не иметь своего офиса, а арендовать один конференц-зал на несколько организаций. Однако целью данной статьи не является поиск оптимальных возможностей работы проектных организаций. Цель статьи рассмотреть проблемы образования как в аспекте его глобальной информатизации, так и в аспекте дистанционного подхода к решению проблем образования.

Совершенно однозначно понятно, что дистанционное образование одна из важных компонент современного непрерывного образования [1]. Вместе с тем, как опыт работы со школьниками и студентами в «допандемийный» период, так, в ещё большей степени - опыт проведения занятий в период пандемии и вынужденной изоляции как учащихся, так и преподавателей показал, что прямая трансляция методов менеджмента, применяемая к сотрудникам различных организаций на учащихся не работает. Вероятно, в первую очередь, проблема связана с мотивацией и уровнем ответственности, а также с уровнем социальной зрелости. Взрослый 


\section{ОБРАЗОВАТЕЛЬНЫЕ ТЕХНОЛОГИИ В СОВРЕМЕННОМ УЧЕБНО-ВОСПИТАТЕЛЬНОМ ПРОСТРАНСТВЕ}

(предполагается - достаточно мотивированный, ответственный и социально зрелый) работник будет выполнять работу в удобное для него время, но представлять результат вол время, удобное заказчику (руководству). В противном случае с сотрудником расстанутся. Учащийся, школьник или студент, прекрасно отдаёт себе отчет, что расстаться с ним для образовательной организации проблематично (для школы - практически невозможно). Это приводит к существенному снижению мотивации к учёбе. Кроме того, крайне отрицательно и демотивирующе действует на учащихся, особенно старшего школьного возраста и студентов качество подготовки дистанционного материала преподавателями. Существует большое количество специальных как аппаратных, так и программных средств для образования. Но они и/или: платные, сложные в освоении, недоступны и труднодоступны для личного использования. Однако возможность создания цифрового контента для целей образования доступна и простыми средствами. В институте физики и прикладной математики Национального исследовательского университета МИЭТ проводился полный цикл занятий лекционных, практических и лабораторных как с использованием общеуниверситетского оборудования для записи лекций и практических занятий, так и дистанционное, но не виртуальное (!) проведение лабораторного практикума. В данной статье рассмотрим методы подготовки материала дистанционной лекции и практического занятия с использованием исключительно доступного оборудования.

Для проведения фото- и видеосъёмки использовался сотовый телефон. Подготовка и оформление теоретического материала проводилось в редакторе презентаций Microsoft PowerPoint, озвучивание - либо средствами редактора презентаций, либо с помощью программы Audacity, доступной для бесплатного скачивания. Предполагая, что план занятия уже составлен, алгоритм создания контента следующий. Готовится обычная презентация. К каждому слайду в области «Заметки к слайду» пишется текст к данному слайду. Желательно, чтобы длительность текста к слайду не превышала 60 секунд. Это требование обусловлено тем, что длительность анимации на каждом слайде ограничена именно таким интервалом времени. При необходимости создания более длинного текста с единым визуальным содержанием слайд дублируется. При необходимости на слайд можно поместить не только рисунки, но и сделанные специально для данного занятия фотографии. Текстовый материал каждого слайда записывается в 


\section{ОБРАЗОВАТЕЛЬНЫЕ ТЕХНОЛОГИИ В СОВРЕМЕННОМ УЧЕБНО-ВОСПИТАТЕЛЬНОМ ПРОСТРАНСТВЕ}

аудиоформате и размещается на слайде. Необходимо в режиме анимации поместить аудио в начало списка анимаций к слайду, назначая всем аннимированым объектам начало «с предыдущим». Наибольшую трудность представляет процедура согласования видеоряда с текстом. Это процедура наиболее длительная при создании записи, но её качественное выполнение приводит к получению вполне профессионального обучающего фильма. Под согласованием видеоряда со звуком понимается, что когда произносится фраза «Согласно второму закону Ньютона...» на экране именно в это время появляется формула второго закона. Правильно используя стили и параметры эффектов анимации, можно добиться эффекта присутствия на обычной лекции. Так, формулы появляются не выпрыгивая из угла, а «пишутся» слева направо, стрелки от одного объекта к другому не плывут через весь экран, а рисуются от начала к концу, как это происходило бы на обычной доске. Возможность входа/выхода объекта при анимации позволяет имитировать не только написание, но и стирание. Это удобно применять при выделении объектов. Так, при необходимости кратковременно обратить внимание на часть экрана, её можно обвести кружком (овалом) или рисованной кривой, используя стиль входа «часовая стрелка», а затем убрать выделение, используя стиль выхода «часовая стрелка» или «растворение». Основные требования к анимации - объекты не должны мельтешить в глазах при появлении и исчезновении, стилей анимации в одной презентации не должно быть слишком много, и, как уже говорилось выше, анимация должна быть согласована со звуком.

Затем презентация сохраняется в формате «Видео MPEG-4» и размещается на канале YouTube. Пример подобной лекции с большим количеством формул и с использованием анимации PowerPoint приведен в [2]

Отдельно отметим следующую особенность интерактивного обучения. Далеко не все учащиеся способны воспринимать материал в течение стандартной пары - 90 минут. Делать же перерыв в присмотре теоретического материала в местах, логически не предусмотренных автором (лектором) не целесообразно. Избежать информационной перегрузки можно, делая видео меньшей продолжительности, от шести до десяти минут. Наш опыт показывает, что объединять короткие части можно с помощью Гугл-тестов, в которых предусмотрено внедрение видел с канала YouTube. Внедрённые в Гугл-тесты видео можно чередовать с коротким тестом по просмотренному 


\section{ОБРАЗОВАТЕЛЬНЫЕ ТЕХНОЛОГИИ

материалу, актуализирующему и фиксирующему его. Пример подобного материала доступен в [3].

Ещё одной технологической возможностью создания видеоконтента является использование графического планшета с возможностью записи экрана с аудиосопровождением или записи с использование микрофона и камеры сотового телефона. Примеры использования планшета и записи через телефон приведены, соответственно, в [4] и [5]. Более подробное рассмотрение этих методов создания видео и их возможностей интересно и перспективно, но выходит за рамки данной стати.

\section{Список литературы}

1. Гундырев В.Б. Интерактивные методы и информационнокоммуникационные технологии как процедура и средства современного инженерного образования / В.Б. Гундырев и др. // Современные исследования социальных проблем (электронный научный журнал). 2014. № 4. doi: 10.12731/2218-7405-2014-4-16.

2. Лекция 2 Волны Гундырев В.Б. [любительское видео] // YouTube. 28 февраля. (https://youtu.be/2RQDWaW8GaI). (дата обращения 16.06.2021)

3. ПРИТ Тест к лекционному занятию «Дифракция Фраунгофера» [Электронный ресурc]. - URL: https://forms.gle/sGvD2jqzURAGVTH88 (Дата обращения 16.06.2021.)

4. Жаркова А. (2020) Задача 3.3 из пособия И.Е. Иродова [любительское видео] // YouTube. 30 мая. (https://youtu.be/n7EYOjJHs48). (дата обращения 16.06.2021)

5. Гундырев В.Б. (2020) Вывод формулы для колец Ньютона [любительское видео] // YouTube. 3 марта. (https://youtu.be/ZnA1UpmO_vA) (дата обращения 16.06.2021) 